\title{
Microfollicular thyroid adenoma and congenital goitrous hypothyroidism
}

\author{
A J Alabbasy, L Delbridge, R Eckstein, C Cowell, M Silink
}

\begin{abstract}
Three patients with congenital goitrous hypothyroidism are reported. They were treated with adequate thyroxine replacement and developed well defined microfollicular thyroid adenomas despite being euthyroid clinically and biochemically throughout their clinical course. Patients with congenital goitrous hypothyroidism appear to be at increased risk of developing thyroid adenoma in childhood despite the use of replacement thyroxine treatment in physiological doses.
\end{abstract}

(Arch Dis Child 1992;67:1294-5)

Congenital goitrous hypothyroidism due to a primary biochemical defect of thyroid biosynthesis accounts for approximately $10-15 \%$ of all congenital hypothyroidism detected at screening in Western countries. ${ }^{1}$ The goitre is presumed to be due to thyrotrophin stimulating hormone (TSH) overstimulation in response to low thyroid hormone concentrations causing hyperplasia of the dysfunctional thyroid tissue. ${ }^{2}$ This process may lead to the development of adenomatous growth and rarely malignant transformation. ${ }^{2}$ We report three patients with this condition who developed well defined, encapsulated microfollicular adenomas despite adequate thyroxine replacement.

\section{Case reports}

CASE 1

A boy was referred at the age of 3.3 years with a goitre present since birth. Clinically he was euthyroid. Investigations revealed free thyroxine index (FTI) 95 (normal 65-150), TSH 32 $\mathrm{mU} / 1$ (normal <7), and a diffusely enlarged goitre with avid uptake on a technetium thyroid scan. The perchlorate discharge test did not suggest a peroxidase deficiency.

When thyroxine treatment was given the gland regressed to a normal size. Thyroxine requirements were monitored by thyroid function studies and TSH measurements at intervals of three to six months. He remained euthyroid clinically and biochemically and at the age of 11.7 years presented with a thyroid nodule. Ultrasonography revealed mildly enlarged thyroid lobes, and a well defined solid mass in the left lobe. At operation a $1.8 \mathrm{~cm}$ diameter microfollicular adenoma of fetal type was removed.

CASE 2

This girl was detected on the neonatal screening programme at the age of 2 weeks and a diagnosis of congenital goitrous hypothyroidism secondary to peroxidase deficiency was made on the basis of avid uptake on thyroid scan and a positive perchlorate discharge test. The initial thyroid function tests were triiodothyronine resin uptake $0.65 \mathrm{nmol} / \mathrm{l}$ (normal 0.80-1.20), thyroxine $18 \mathrm{nmol} / /$ (normal 100-215), FTI 12 (normal 75-200) and TSH $620 \mathrm{mU} / 1$ (normal 1-15).

Her thyroxine replacement was monitored at intervals of three months, and throughout the next four years the TSH remained $<7 \mathrm{mU} / 1$ except for two occasions (at the age of 2 and 4 years) when it was transiently increased, reaching concentrations of $17 \cdot 5$ and $11.5 \mathrm{mU} / \mathrm{l}$ respectively. The FTI remained in the range 126-192 at all times (normal 50-180).

At the age of 4.25 years a thyroid nodule was detected clinically. A thyroid scan revealed a hyperfunctioning thyroid nodule in the left lobe. At operation a $2 \mathrm{~cm}$ diameter microfollicular adenoma of fetal type was removed. A similar $0.2 \mathrm{~cm}$ adenoma was present in the adjacent thyroid tissue. The follicular epithelial cells showed variable hyperplasia and nuclear enlargement (figure).

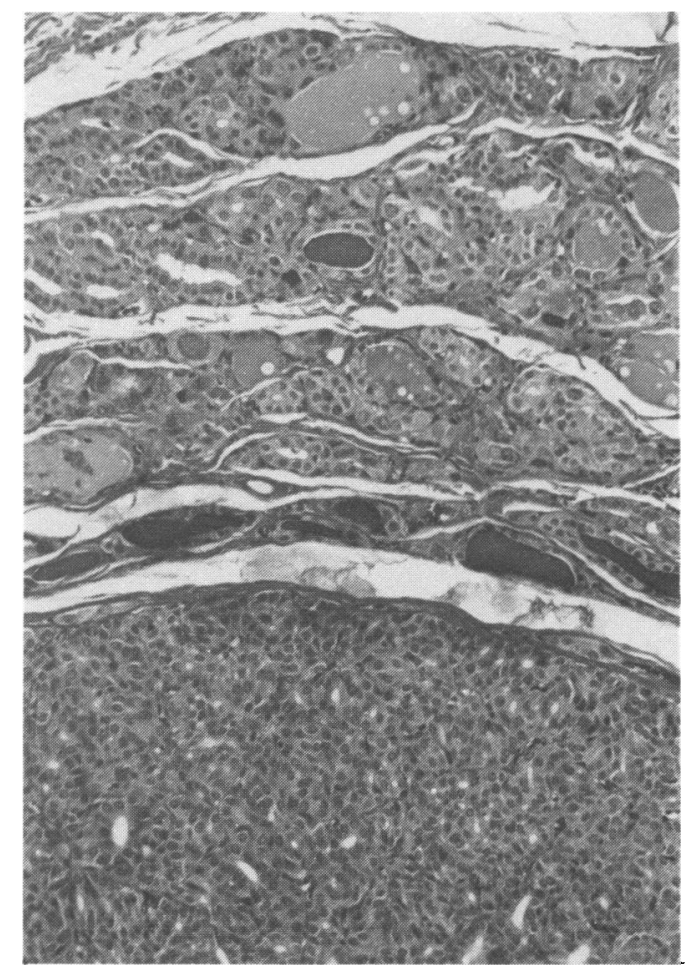

Adenoma and adjacent hyperplastic thyroid tissue of case 2 (haematoxylin and eosin $\times 130$ ). 
CASE 3

This boy had congenital goitrous hypothyroidism diagnosed at 9 months of age when he presented with the classical clinical features of hypothyroidism. This was confirmed by the thyroxine measurement of 30 nmol/ (normal 75-160) and TSH >400 mU/1 (normal <7). The thyroid scan showed an enlarged thyroid gland with moderately enhanced but uniform uptake.

Replacement thyroxine treatment was started with a good clinical and biochemical response. His thyroxine and TSH remained within normal ranges throughout the next 11 years.

At the age of 12.5 years he presented with a nine month history of a nodular goitre. On palpation the left lobe was $5 \times 4 \mathrm{~cm}$ and the right $3.5 \times 4 \mathrm{~cm}$. Thyroid ultrasound identified multiple solid nodules involving both lobes of the thyroid gland. The largest mass measured $3 \times 3 \times 3.5 \mathrm{~cm}$ in the left lobe and corresponded to a large well demarcated solid nodule.

Total thyroidectomy was performed. The cut surface showed several well demarcated colloid nodules with a $2.5 \mathrm{~cm}$ diameter fleshy nodule in the left lower lobe. The large nodule in the left lobe was well circumscribed follicular adenoma showing microfollicular and embryonal growth pattern. Elsewhere in the thyroid tissue there were numerous nodules showing quite variable cellularity.

\section{Discussion}

These patients had hypothyroidism secondary to dyshormonogenesis. The positive perchlorate discharge test in case 2 suggests an organification defect, ${ }^{3}$ while the normal perchlorate discharge test in case 1 would suggest a diagnosis of one of the other metabolic abnormalities such as deiodinase, coupling, or thyroglobulin defects. ${ }^{3}$ All remained euthyroid clinically and biochemically but despite the seemingly adequate thyroxine replacement they developed microfollicular adenomas.

Histologically, congenital goitrous hypothyroidism is characterised initially by diffuse hyperplasia. Nodules and adenomas develop over time and typically are very cellular, showing embryonal or fetal architecture. ${ }^{2}$ As a result the histological distinction between adenoma and nodule may not be clear cut. Hyperplasia and cellular pleomorphism may be so marked as to mimic malignant transformation, but genuine malignancy appears to be a rare event, only six cases being accepted in the literature review of Cooper et al. ${ }^{2}$

In contrast to our patients, most cases previously described were long term hypothyroid or on sporadic thyroxine replacement with excessive stimulation of TSH. Our patients unexpectedly developed true adenomas despite strict clinical and biochemical follow up, suggesting sensitivity of the patients' thyroid follicles to the effects of normal TSH concentrations. This is supported by the histological observation of diffuse hyperplasia in cases 2 and 3 as well as the presence of multiple small adenomas in case 3 . Recent evidence suggests that there are many other thyroid growth promoting agents including vasoactive inhibitory peptide 4 and epidermal growth factor. 5

We conclude that although patients with congenital goitrous hypothyroidism are partially protected from the development of nodular goitre by adequate thyroxine replacement treatment, they remain at risk of developing follicular adenomas as a result of persistent low concentration TSH stimulation. Thyroxine replacement treatment will reduce but not eliminate the development of adenomas.

1 Fisher DA, Dussault JH, Folley TP, et al. Screening for .

2 Cooper DS, Axelrod L, DeGroot LJ, Vickery AI, Maloof F. Congenital goitre and the development of metastatic follicular carcinoma with evidence for a leak of nonhormonal iodide: clinical, pathological kinetic and biochemical studies and a review of the literature. $\boldsymbol{f}$ Clin Endocrinol Metab 1981;52:294-306.

3 Stanbury JB, Dumont JE. Familial goitre and related disorders. In: Stanbury JB, Wyngaarden J, Fredrickson DS, orders. In: Stanbury JB, Wyngaarden J, Fredrickson DS, inherited disease. New York: McGraw-Hill, 1983:231-69.

4 Siperstein AE, Miller RA Clark OH. Stimulatory effect of asoactive intestinal polypeptide on human normal an Weoplastic thyroid tissue. Surgery 1988;104;985-91. Location of epidermal growth factor receptors on procine thyroid follicle cells and receptor regulation by thyrotropin. Endocrinology 1985;118:1040-6. 